\title{
BMJ Open Knowledge, attitudes and practices regarding infant feeding among HIV-infected pregnant women in Gaborone, Botswana: a cross-sectional
} survey

\author{
Justina Ndubuka, ${ }^{1}$ Nnamdi Ndubuka, ${ }^{2}$ Ying Li, ${ }^{3,4}$ Caitlin M Marshall, ${ }^{4}$ John Ehiri ${ }^{4}$
}

To cite: Ndubuka J, Ndubuka N, Li Y, et al. Knowledge, attitudes and practices regarding infant feeding among HIV-infected pregnant women in Gaborone, Botswana: a cross-sectional survey. BMJ Open 2013;3:e003749. doi:10.1136/bmjopen-2013003749

- Prepublication history for this paper is available online. To view these files please visit the journal online (http://dx.doi.org/10.1136/ bmjopen-2013-003749).

Received 7 August 2013 Revised 7 November 2013 Accepted 7 November 2013

CrossMark

For numbered affiliations see end of article.

Correspondence to Professor John Ehiri; jehiri@email.arizona.edu

\section{ABSTRACT}

Objectives: To assess knowledge, attitudes and practices regarding infant feeding among HIV-positive pregnant women in Gaborone, Botswana, and factors that influence their infant feeding choices.

Design: A cross-sectional study.

Methods and study setting: A questionnaire survey of 96 HIV-positive pregnant women attending four public infectious disease control clinics in Gaborone, Botswana.

Results: Only about half of the study participants had knowledge about prevention of mother-to-child transmission (PMTCT) services related to breastfeeding, and very few (19.8\%) chose to breastfeed their infants exclusively. Results of multiple logistic regression analysis showed that receiving infant feeding counselling as part of the PMTCT programme was significantly associated with a decision to exclusively breastfeed $(\mathrm{OR}(95 \% \mathrm{Cl}) 5.38$ (1.83 to 15.81)). Similarly, HIV-positive pregnant women who received breastfeeding counselling through the PMTCT programme had higher knowledge of PMTCT practices related to appropriate infant feeding (OR $(95 \% \mathrm{Cl}) 5.91$ (1.06 to 34.31)). Women who did not express concern about HIV stigma had significantly higher knowledge of PMTCT practices related to infant feeding (OR $(95 \%$ Cl) 5.91 (1.69 to 15.56)). Knowledge of PMTCT practices related to breastfeeding was negatively associated with the belief that breastfeeding could transmit HIV to the baby $(\mathrm{OR}(95 \% \mathrm{Cl}) 9.73$ (3.37 to 28.08)).

Conclusions: Knowledge, attitudes and practices related to breastfeeding among HIV-positive pregnant women need further improvement, and the PMTCT programme should strengthen infant feeding counselling services to assist HIV-positive mothers in making informed and appropriate decisions regarding infant feeding.

\section{INTRODUCTION}

Epidemiological data from the Joint United Nations Program on AIDS estimate the

\section{Strengths and limitations of this study}

- The results of this study provide a snapshot assessment of the quality of implementation of Botswana's prevention of mother-to-child transmission (PMTCT) guidelines.

- The main limitation is that only HIV-infected pregnant women who attended the four participating infectious disease control clinics were included in the study. This limits the ability to generalise findings to all HIV-infected pregnant women in Botswana's National PMTCT programme.

- The findings of this study provide valuable information for improving the quality of programs to prevent mother to child transmission of HIV in the study setting and other locales.

prevalence of HIV among adults aged 1549 years in Botswana to be $23.40 \%$, with more than 160000 women aged 15-49 years currently living with HIV/AIDS. ${ }^{1}$ According to the Republic of Botswana's Global AIDS Response Report prepared in collaboration with the Botswana National AIDS Coordinating Agency (NACA), the national prevalence of HIV among pregnant women aged $15-49$ years is $30.4 \%$, with an estimated 13072 HIV-infected women giving birth annually. ${ }^{2}{ }^{3}$ In the absence of interventions to prevent transmission during pregnancy, delivery or breastfeeding for HIV-infected pregnant women, it is estimated that $35 \%$ of births will result in mother-to-child transmission (MTCT) of HIV. ${ }^{3}{ }^{4}$ According to the WHO, if effective interventions are implemented to prevent MTCT (PMTCT), the rate can be reduced to less than $5 \%{ }^{4}$

Owing to the transmissibility of HIV from mother to child, the feeding of HIV-exposed infants remains a significant challenge in controlling the spread of HIV/AIDS. The 
dilemma concerning feeding infants of HIV-positive mothers is how to balance the risk of HIV transmission through breastfeeding with the risk of death from causes other than HIV such as pneumonia, diarrhoeal diseases and malnutrition among formula-fed infants. ${ }^{5}$ Exclusive breastfeeding (EBF) plays a critical role in the overall health of infants. It is estimated that $3 \%$ of all under-5 mortalities in low-income countries could be prevented through optimal breastfeeding during the crucial first year of life. ${ }^{6}$ Optimal breastfeeding is considered to be EBF for the first 6 months of life, followed by continued breastfeeding combined with safe and nutritionally adequate complementary feeding up to 24 months of age. ${ }^{7-9} \mathrm{EBF}$ is regarded as a global health goal given its strong association with reduced morbidity and mortality, particularly in low-income countries where safe water and sanitation are often lacking. ${ }^{10}$

In 2011, the Government of Botswana (GoB) revised the Botswana National PMTCT guidelines and initiated the use of highly active antiretroviral therapy (HAART) for all HIV-infected pregnant women regardless of their CD4 cell count. The goal was PMTCT of HIV by providing HAART to pregnant women who would otherwise not qualify for treatment, based on their $\mathrm{CD} 4$ cell count. ${ }^{3}$ For many years, the GoB had recommended that HIV-infected women exclusively formula feed their infants and provide infant formula free of charge until the infant is 1 year of age to support this recommendation. ${ }^{3}$ However, in 2011, the Botswana Ministry of Health $(\mathrm{MoH})$ recommended exclusive formula feeding (EFF) for the first 6 months of life only for women for whom formula feeding is acceptable, feasible, affordable, sustainable and safe (AFASS). ${ }^{311} 12$ Botswana has one of the most comprehensive maternal and child health services in sub-Saharan Africa, with nearly $95 \%$ of pregnant women receiving prenatal care and having their deliveries attended to by a health professional in a health facility. ${ }^{9}$ During prenatal visits, all pregnant women regardless of their HIV status are provided with education and counselling according to the country's infant and young child-feeding guidelines (based on the WHO 2010 recommendations ${ }^{9}$ ) to ensure that they make informed and appropriate infant feeding choices. ${ }^{39}$ They are also assessed for AFASS using the following criteria: piped water in the house or yard (safety); electricity, gas or paraffin for cooking fuel (feasibility); disclosure of HIV status within 3 weeks after birth (acceptability); having someone in the household employed (affordability and sustainability) and access to a fridge for storage of prepared formula (safety). Depending on the outcome of the AFASS assessment, HIV-infected pregnant women are supported in their decision to either formula feed or breastfeed their infant. For HIV-positive mothers for whom formula feeding is not AFASS, optimal breastfeeding should be recommended and strongly encouraged.

EBF has traditionally been promoted as an important intervention to prevent child morbidity and mortality in low-income countries. In addition to the nutritional value of breast milk for infants during their first months of life, dependence on breast milk not only reduces their exposures to contaminated food and drinks, but also protects them against diarrhoea through the antiinfective properties of breast milk. With the emergence of evidence linking breastfeeding with MTCT of HIV, many women are conflicted on the issue of whether or not to breastfeed their babies. Research evidence has also shown that poor-quality counselling in PMTCT programmes and the effects of mass media have created widespread confusion for HIV-infected mothers regarding feeding their infant despite the presence of national guidelines. ${ }^{13}$ Women who may be confused by these messages often fail to receive advice to practise EBF, which may result in mixed feeding and an increased risk of HIV transmission. ${ }^{14}$ The main objectives of the study were to identify factors that influence infant feeding choices of HIV-infected pregnant women, to provide data for evidence-based decision to improve the quality of Botswana's PMTCT programme, and to allow the Botswana MoH to assess implementation of the revised guidelines in order to strengthen future efforts. It is hoped that findings from this study will be of value not only to the Botswana AIDS Control Program, but also to other PMTCT programmes in sub-Saharan Africa and other low and middle countries where paediatric HIV/ AIDS is a public health challenge.

\section{METHODS}

A cross-sectional design was used for the study.

\section{Setting}

The study was conducted in four public infectious disease control clinics (IDCCs) in Gaborone, Botswana, managed by the Gaborone City Council. These clinics were selected because the study population of interest (eligible HIV-infected pregnant women) provides access to universal HAART prophylaxis and thus constitutes a reliable sampling frame from which participants were recruited.

\section{Study population}

The study population included all HIV-infected pregnant women attending IDCCs in Gaborone for universal HAART programme services during the study period. All HIV-infected pregnant women who presented at any of the four IDCCs during the study period had an equal and independent chance of being included in the study. ${ }^{15}$ HIV-infected pregnant women who were Botswana citizens, aged 21 years and above, and willing to participate in the study by providing informed consent were eligible for inclusion. During informed consent, the rationale for the study was explained to potential respondents (in the local language, Setswana) and their voluntary participation was sought. All respondents were informed that their participation was voluntary, and that if they chose not to participate, they would 
not lose any benefits from their health facility. They were also informed of their right to withdraw from the study at any time. Women who volunteered to participate in the study were asked to sign the inform consent form. Those who could not read or write were asked to give their thumbprint as a confirmation of their consent. Thus, participation in the study was entirely voluntary and no incentives were provided to respondents. Respondents were assured of confidentiality, and only study unique identification numbers were used on the questionnaires.

\section{Data collection}

Data were collected using a structured, intervieweradministered questionnaire. Eligible respondents were interviewed and data were transcribed from their medical records onto the questionnaire. The questionnaire consisted of 33 items that were constructed based on a review of the literature. ${ }^{16}$ The questionnaire was translated into the local language (Setswana) and pretested on five IDCC attendees who were not involved in the final survey. The questionnaire had the following subsections: sociodemographic information, clinical information, knowledge about PMTCT and infant feeding practices/intentions. Items of the questionnaire elicited information on participants' sociodemographic characteristics, their knowledge of the objectives of HAART, knowledge of MTCT of HIV, strategies to reduce MTCT of HIV during pregnancy, knowledge of infant feeding practices in the context of HIV, the benefits of EBF, knowledge of the role of mixed feeding (breastfeeding and formula feeding) in MTCT of HIV, access to infant feeding counselling in the context of HAART, infant feeding choices and reasons for the choices, important persons in the decision to breastfeed or formula feed, etc. Data were collected over a period of 4 weeks (11 June-9 July 2012) through interviews administered by an interpreter who was fluent in the local language (Setswana) and received training on ethical conduct of research and data collection.

\section{Data analysis}

All questionnaires were entered onto an Excel spreadsheet and checked for accuracy and completeness. The data were then exported to the Statistical Package for Social Sciences (SPSS) V.19 for analysis. With regard to knowledge of PMTCT and PMTCT practices during breastfeeding, we first provided a summary of the number of correct responses by participants and later categorised the responses as either 'high' knowledge, when a respondent responded correctly to all of the questions, or 'low' knowledge when a participant responded incorrectly to one or more of the questions. Descriptive statistics were used to describe and summarise other variables such as sociodemographic characteristics of respondents, clinical information, knowledge of PMTCT and the important person in decision-making on infant feeding choices. ${ }^{15}$ Pearson $\chi^{2}$ or Fisher's exact test was used to compare results between groups. Multiple logistic regression analyses were also employed to control for possible confounding factors and to assess the separate effects of the study variables. ORs with $95 \%$ CI were computed to assess factors associated with the choice of breastfeeding, knowledge of PMTCT and PMTCT practices related to breastfeeding. A two-tailed probability level of $\mathrm{p}<0.05$ was chosen as the level of statistical significance.

\section{RESULTS}

\section{Characteristics of respondents}

Of a total of 102 women from the IDCCs who were eligible for inclusion in the study, 96 volunteered to participate, yielding a response rate of $94.1 \%$. The demographic characteristics of participants, including age, marital status, education, employment status and parity, are shown in table 1. Respondents aged 21-25 years constituted the majority $(43.8 \%$; $\mathrm{n}=42)$. With regard to marital status, a majority $(92.7 \%, \mathrm{n}=89)$ of the respondents identified themselves as single or cohabiting. Only $7.3 \%(n=7)$ had university-level education. Regarding the employment status of the respondents, $39.6 \%(n=38)$ were unemployed during the study period. About half of the study participants $(53.1 \%$; $n=51)$ had $1-2$ children, and $34.4 \% \quad(n=33)$ were pregnant for the first time.

All respondents were taking some form of HAART regimen at the time of the study. Table 1 shows that a majority of the respondents $(85.4 \% ; \mathrm{n}=82)$ indicated that they received Atripla as their HAART regimen while $6.3 \%(\mathrm{n}=6)$ received a combination of Combivir and nevirapine $(\mathrm{CBV}+\mathrm{NVP})$. As shown in table 1 , nearly half of the respondents $(55.2 \%$; $=53)$ identified their husbands/partners as the most influential individual with regard to their choice of infant feeding method. Only 66 of the respondents $(70.2 \%)$ indicated that they were counselled on infant feeding options recommended for HIV-infected women.

As for knowledge, attitudes and practice (KAP) related to breastfeeding among the respondents, $56.3 \%$ of respondents believed that an infant of an HIV-infected mother could become infected with HIV when breastfed, and $88.4 \%$ were concerned about AIDS stigma related to HIV and infant feeding choices. Only about half of the respondents had high knowledge about PMTCT and PMTCT-related practices related to breastfeeding. Less than one in five $(19.8 \%)$ made the decision to exclusively breastfeed their babies (table 1).

\section{Knowledge and practices related to breastfeeding among HIV-infected pregnant women}

Data on knowledge and choice of breastfeeding method are presented in table 2. Pearson $\chi^{2}$ (or Fisher's exact test) was used to determine associations between categorical data. Multiple logistic regression analysis was used to assess factors associated with knowledge and choice of infant feeding method. Results indicated that 
Table 1 Characteristics of participants $(\mathrm{N}=96)$

\begin{tabular}{|c|c|c|}
\hline Characteristics & $\mathbf{N}$ & Per cen \\
\hline \multicolumn{3}{|l|}{ Age group (years) } \\
\hline $21-25$ & 42 & 43.8 \\
\hline $26-30$ & 30 & 31.3 \\
\hline $31-35$ & 18 & 18.8 \\
\hline $36-40$ & 5 & 5.2 \\
\hline $41-45$ & 1 & 1 \\
\hline \multicolumn{3}{|l|}{ Marital status } \\
\hline Single & 41 & 42.7 \\
\hline Married & 4 & 4.2 \\
\hline Cohabiting & 48 & 50.0 \\
\hline Separated & 3 & 3.1 \\
\hline \multicolumn{3}{|l|}{ Educational level } \\
\hline Primary school & 15 & 15.6 \\
\hline Junior secondary & 29 & 30.2 \\
\hline Junior secondary with additional training & 8 & 8.3 \\
\hline Senior secondary & 27 & 28.1 \\
\hline College or vocational training & 10 & 10.4 \\
\hline University & 7 & 7.3 \\
\hline \multicolumn{3}{|l|}{ Employment status } \\
\hline Unemployed & 38 & 39.6 \\
\hline Government employee & 8 & 8.3 \\
\hline Private employee & 37 & 38.5 \\
\hline Self-employed & 7 & 7.3 \\
\hline Volunteer & 2 & 2.1 \\
\hline Student & 4 & 4.2 \\
\hline \multicolumn{3}{|l|}{ Parity } \\
\hline $1-2$ & 51 & 53.1 \\
\hline $3-4$ & 10 & 10.4 \\
\hline 5 or more & 2 & 2.1 \\
\hline None & 33 & 34.4 \\
\hline \multicolumn{3}{|l|}{ HAART regimen received } \\
\hline Atripla (FTC+TDF+EFV) & 81 & 84.4 \\
\hline $\mathrm{CBV}+\mathrm{NVP}$ & 6 & 6.3 \\
\hline \multirow{2}{*}{\multicolumn{3}{|c|}{ TDF+FTC+Kaletra }} \\
\hline & & \\
\hline Others & 4 & 4.2 \\
\hline \multicolumn{3}{|l|}{ Reasons for receiving HAART } \\
\hline РMTCT (Universal HAART) & 66 & 68.8 \\
\hline Maternal treatment & 30 & 31.3 \\
\hline
\end{tabular}

Most important person in making-decision on infant feeding

My father 33.1

My husband/partner $\quad 53 \quad 55.2$

My mother $\quad 3233.3$

$\begin{array}{lll}\text { My sister } & 5 & 5.2\end{array}$

$\begin{array}{llll}\text { My aunt } & 3 & 3.1\end{array}$

Received infant feeding counselling during ANC ( $N=94)$

Yes $\quad 66 \quad 70.2$

$\begin{array}{lll}\text { No } & 28 & 29.8\end{array}$

Chose to breastfeed

$\begin{array}{lrr}\text { Yes } & 19 & 19.8\end{array}$

No $\quad \begin{array}{lll}77 & 80.2\end{array}$

Believe breastfeeding transmits HIV to baby

Yes $\quad 54 \quad 56.3$

$\begin{array}{lll}\text { No } & 42 \quad 43.8\end{array}$

Concerned about HIV stigma

$\begin{array}{lll}\text { Yes } & 84 & 88.4\end{array}$

No $11 \quad 11.6$

Continued

\begin{tabular}{lrc}
\hline Table 1 Continued & & \\
\hline Characteristics & N & Per cent \\
\hline Knowledge of PMTCT & 4 & 4.2 \\
1 correct response & 17 & 17.7 \\
2 correct responses & 25 & 26.0 \\
3 correct responses & 50 & 52.1 \\
4 correct responses & 1 & 1.0 \\
Knowledge of PMTCT related to breastfeeding & \\
1 correct response & 0 & 0.00 \\
2 correct responses & 2 & 2.1 \\
3 correct responses & 5 & 5.2 \\
4 correct responses & 13 & 13.5 \\
5 correct responses & 26 & 27.1 \\
6 correct responses & 49 & 51.0 \\
7 correct responses & & \\
\hline
\end{tabular}

CBV, combivir; EFV, Efavirenz; FTC, emtricitabine; HAART, highly active antiretroviral therapy; NVP, nevirapine; PMTCT, prevention of mother-to-child transmission; TDF, tenofovir.

receiving infant feeding counselling as part of the PMTCT programme was significantly associated with the decision to exclusively breastfeed (OR (95\% CI) 5.38 (1.83 to 15.81)). Receiving infant infant feeding counselling as part of the PMTCT programme was also significantly associated with high knowledge of PMTCT practices related to breastfeeding (OR $(95 \%$ CI) 5.91 (1.06 to 34.31)). Women who did not express concern about AIDS stigma had significantly higher knowledge of PMTCT practices related to infant feeding (OR $(95 \%$ CI) 5.91 (1.69 to 15.56)). Knowledge of PMTCT practices related to breastfeeding was negatively associated with the belief that breastfeeding could transmit HIV to the baby (OR (95\% CI) 9.73 (3.37 to 28.08$)$ ).

\section{DISCUSSION}

The basic ethical principle of 'informed choice' requires that HIV-positive women are provided with adequate information about their infant feeding options in the context of PMTCT of HIV. ${ }^{17}$ This study observed that only about half of the HIV-infected women had knowledge of PMTCT and PMTCT practices related to breastfeeding. This finding is similar to that demonstrated by Hailu $^{18}$ who found that only $30.5 \%$ of women in Jimma, Ethiopia had sufficient knowledge of infant feeding options recommended for HIV-positive women. ${ }^{18}$ Results revealed that counselling on infant feeding provided as part of the PMTCT programme was significantly associated with knowledge of PMTCT practices related to breastfeeding (OR (95\% CI) 5.91 (1.06 to 34.31)). Although the Botswana National PMTCT guideline recommends that all pregnant women be counselled on infant feeding choices, only $70 \%$ of the respondents indicated that they received such counselling. This suggests that gaps exist within the PMTCT programme guidelines and actual practice. 
Table 2 Respondents' knowledge of PMTCT and choice of breastfeeding

\begin{tabular}{|c|c|c|c|c|c|c|c|c|}
\hline \multirow[b]{2}{*}{ Variable } & \multicolumn{2}{|c|}{$\begin{array}{l}\text { Choice of exclusive } \\
\text { breastfeeding }\end{array}$} & \multicolumn{2}{|c|}{$\begin{array}{l}\text { Knowledge about } \\
\text { PMTCT }\end{array}$} & \multicolumn{2}{|c|}{$\begin{array}{l}\text { Knowledge about } \\
\text { PMTCT practice } \\
\text { related to } \\
\text { breastfeeding }\end{array}$} & \multicolumn{2}{|c|}{$\begin{array}{l}\text { Breastfeeding } \\
\text { transmits HIV to baby }\end{array}$} \\
\hline & $\begin{array}{l}\text { Yes, No. } \\
(\%)\end{array}$ & $\begin{array}{l}\text { No, No. } \\
(\%)\end{array}$ & $\begin{array}{l}\text { High No. } \\
(\%)\end{array}$ & $\begin{array}{l}\text { Low No. } \\
(\%)\end{array}$ & $\begin{array}{l}\text { High No. } \\
(\%)\end{array}$ & $\begin{array}{l}\text { Low No. } \\
(\%)\end{array}$ & $\begin{array}{l}\text { Yes, No. } \\
(\%)\end{array}$ & $\begin{array}{l}\text { No, No. } \\
(\%)\end{array}$ \\
\hline \multicolumn{9}{|l|}{ Age group (years) } \\
\hline $21-25$ & $14(33.3)$ & $28(66.7)$ & $22(52.4)$ & $20(47.6)$ & $25(59.5)$ & $17(40.5)$ & $29(69.0)$ & $13(31.0)$ \\
\hline $26-30$ & $3(10.0)$ & 27 (90.0) & $15(50.0)$ & $15(50.0)$ & $16(53.3)$ & $14(46.7)$ & $16(53.3)$ & $14(46.7)$ \\
\hline $31-35$ & $2(11.1)$ & 16 (88.9) & $10(55.6)$ & $8(44.4)$ & 6 (33.3) & $12(66.7)$ & 7 (38.9) & $11(61.1)$ \\
\hline $36-40$ & $0(0.0)$ & $5(100.0)$ & $2(40.0)$ & $3(60.0)$ & $1(20.0)$ & 4 (80.0) & $2(40.0)$ & $3(60.0)$ \\
\hline 41-45 & $0(0.0)$ & $1(100.0)$ & $1(100.0)$ & $0(0)$ & $1(100.0)$ & $0(0.0)$ & $0(0.0)$ & $1(100.0)$ \\
\hline \multicolumn{9}{|l|}{ Marital status } \\
\hline Single & $12(29.3)$ & $29(70.7)$ & 34 (82.9) & $7(17.1)^{\star}$ & 32 (78.0) & $9(22.0)^{\star}$ & $39(95.1)$ & $2(4.9)^{*}$ \\
\hline Married & $0(0.0)$ & $4(100.0)$ & $3(75.0)$ & $1(25.0)$ & $3(75.0)$ & $1(25.0)$ & $2(50.0)$ & $2(50.0)$ \\
\hline Cohabiting & $6(12.5)$ & $42(87.5)$ & $12(25.0)$ & $36(75.0)$ & $13(27.1)$ & 35 (72.9) & $13(27.1)$ & 35 (72.9) \\
\hline Separated & $1(33.3)$ & $2(66.7)$ & 1 (33.3) & $2(66.7)$ & 1 (33.3) & $2(66.7)$ & $0(0.0)$ & $3(100.0)$ \\
\hline \multicolumn{9}{|l|}{ Educational level } \\
\hline Primary school & 5 (33.3) & $10(66.7)$ & $13(86.7)$ & $2(13.3)^{*}$ & $9(60.0)$ & $6(40.0)$ & $13(86.7)$ & 2 (13.3) \\
\hline Junior secondary & $6(20.7)$ & $23(79.3)$ & $19(65.5)$ & $10(34.5)$ & $14(48.3)$ & $15(51.7)$ & $16(55.2)$ & $13(44.8)$ \\
\hline $\begin{array}{l}\text { Junior secondary } \\
\text { with additional } \\
\text { training }\end{array}$ & $3(37.5)$ & $5(62.5)$ & $3(37.5)$ & $5(62.5)$ & $5(62.5)$ & $3(37.5)$ & $6(75.0)$ & $2(25.0)$ \\
\hline Senior secondary & $4(14.8)$ & $23(85.2)$ & $11(40.7)$ & $16(59.3)$ & $13(48.1)$ & $14(51.9)$ & $13(48.1)$ & $14(51.9)$ \\
\hline $\begin{array}{l}\text { College or } \\
\text { vocational training }\end{array}$ & $1(10.0)$ & $9(90.0)$ & $0(0.0)$ & $10(100.0)$ & $4(40.0)$ & $6(60.0)$ & $3(30.0)$ & $7(70.0)$ \\
\hline University & $0(0.0)$ & $7(100.0)$ & $4(57.1)$ & 3 (42.9) & $4(57.1)$ & 3 (42.9) & 3 (42.9) & $4(57.1)$ \\
\hline \multicolumn{9}{|l|}{ Employment status } \\
\hline Unemployed & $10(26.3)$ & $28(73.7)$ & $23(60.5)$ & $15(39.5)$ & $23(60.5)$ & $15(39.5)$ & $24(63.2)$ & $14(36.8)$ \\
\hline $\begin{array}{l}\text { Government } \\
\text { employee }\end{array}$ & $2(25.0)$ & $6(75.0)$ & $3(37.5)$ & $5(62.5)$ & $3(37.5)$ & $5(62.5)$ & $2(25.0)$ & $6(75.0)$ \\
\hline Private employee & $4(10.8)$ & 33 (89.2) & $15(40.5)$ & $22(59.5)$ & $18(48.6)$ & $19(51.4)$ & $19(51.4)$ & $18(48.6)$ \\
\hline Self-employed & $2(28.6)$ & $5(71.4)$ & $4(57.1)$ & 3 (42.9) & $2(28.6)$ & $5(71.4)$ & $5(71.4)$ & $2(28.6)$ \\
\hline Volunteer & $1(50.0)$ & $1(50.0)$ & $2(100.0)$ & $0(0.0)$ & $1(50.0)$ & $1(50.0)$ & $2(100.0)$ & $0(0.0)$ \\
\hline Student & $0(0.0)$ & $4(100.0)$ & $3(75.0)$ & $1(25.0)$ & $2(50.0)$ & $2(50.0)$ & $2(50.0)$ & $2(50.0)$ \\
\hline \multicolumn{9}{|l|}{ Parity } \\
\hline 2-January & $9(17.6)$ & $42(82.4)$ & 20 (39.2) & $31(60.8)^{*}$ & $20(39.2)$ & $31(60.8)^{*}$ & $22(43.1)$ & $29(56.9)^{*}$ \\
\hline 4-March & $1(10.0)$ & $9(90.0)$ & $9(90.0)$ & $1(10.0)$ & 7 (70.0) & $3(30.0)$ & $8(80.0)$ & $2(20.0)$ \\
\hline 5 or more & $0(0.0)$ & $2(100.0)$ & $2(100.0)$ & $0(0.0)$ & $0(0.0)$ & $2(100.0)$ & $1(50.0)$ & $1(50.0)$ \\
\hline None & $9(27.3)$ & $24(72.7)$ & $19(57.6)$ & $14(42.4)$ & $22(66.7)$ & $11(33.3)$ & $23(69.7)$ & $10(30.3)$ \\
\hline \multicolumn{9}{|c|}{ HAART regimen received } \\
\hline $\begin{array}{l}\text { Atripla } \\
\text { (FTC+TDF+EFV) }\end{array}$ & $17(21.0)$ & $64(79.0)^{*}$ & $43(53.1)$ & $38(46.9)^{*}$ & $42(51.9)$ & $39(48.1)^{*}$ & $48(59.3)$ & $33(40.7)$ \\
\hline $\mathrm{CBV}+\mathrm{NVP}$ & $1(16.7)$ & 5 (83.3) & $2(33.3)$ & $4(66.7)$ & $3(50.0)$ & $3(50.0)$ & $1(16.7)$ & $5(83.3)$ \\
\hline $\begin{array}{l}\text { CBV+Kaletra } \\
\text { TDF+FTC+Kaletra }\end{array}$ & $1(20.0)$ & $4(80.0)$ & $5(100.0)$ & $0(0.0)$ & $4(80.0)$ & $1(20.0)$ & $4(80.0)$ & $1(20.0)$ \\
\hline Others & $0(0.0)$ & $4(100.0)$ & $0(0.0)$ & $4(100.0)$ & $0(0.0)$ & $4(100.0)$ & $1(25.0)$ & $3(75.0)$ \\
\hline \multicolumn{9}{|c|}{ Reasons for receiving HAART } \\
\hline РMTCT & $15(22.7)$ & $51(77.3)$ & $36(54.5)$ & $30(45.5)$ & $36(54.5)$ & $30(45.5)$ & $42(63.6)$ & $24(36.4)^{*}$ \\
\hline Maternal treatment & $4(13.3)$ & $26(86.7)$ & $14(46.7)$ & $16(53.3)$ & $13(43.3)$ & $17(56.7)$ & $12(40.0)$ & $18(60.0)$ \\
\hline \multicolumn{9}{|c|}{ Most important person in making decision on infant feeding } \\
\hline My father & $2(66.7)$ & $1(33.3)$ & $3(100.0)$ & $0(0.0)$ & $1(33.3)$ & $2(66.7)$ & $3(100.0)$ & $0(0.0)$ \\
\hline $\begin{array}{l}\text { My husband/ } \\
\text { partner }\end{array}$ & $10(18.9)$ & $43(81.1)$ & $27(50.9)$ & $26(49.1)$ & $25(47.2)$ & $28(52.8)$ & $30(56.6)$ & $23(43.4)$ \\
\hline My mother & $7(21.9)$ & $25(78.1)$ & $15(46.9)$ & $17(53.1)$ & $19(59.4)$ & $13(40.6)$ & $16(50.0)$ & $16(50.0)$ \\
\hline My sister & $0(0.0)$ & $5(100.0)$ & $4(80.0)$ & $1(20.0)$ & $2(40.0)$ & $3(60.0)$ & $4(80.0)$ & $1(20.0)$ \\
\hline My aunt & $0(0.0)$ & $3(100.0)$ & 1 (33.3) & $2(66.7)$ & $2(66.7)$ & 1 (33.3) & 1 (33.3) & $2(66.7)$ \\
\hline
\end{tabular}


Table 2 Continued

\begin{tabular}{|c|c|c|c|c|c|c|c|c|}
\hline \multirow[b]{2}{*}{ Variable } & \multicolumn{2}{|c|}{$\begin{array}{l}\text { Choice of exclusive } \\
\text { breastfeeding }\end{array}$} & \multicolumn{2}{|c|}{$\begin{array}{l}\text { Knowledge about } \\
\text { PMTCT }\end{array}$} & \multicolumn{2}{|c|}{$\begin{array}{l}\text { Knowledge about } \\
\text { PMTCT practice } \\
\text { related to } \\
\text { breastfeeding }\end{array}$} & \multicolumn{2}{|c|}{$\begin{array}{l}\text { Breastfeeding } \\
\text { transmits HIV to baby }\end{array}$} \\
\hline & $\begin{array}{l}\text { Yes, No. } \\
(\%)\end{array}$ & $\begin{array}{l}\text { No, No. } \\
(\%)\end{array}$ & $\begin{array}{l}\text { High No. } \\
\text { (\%) }\end{array}$ & $\begin{array}{l}\text { Low No. } \\
(\%)\end{array}$ & $\begin{array}{l}\text { High No. } \\
(\%)\end{array}$ & $\begin{array}{l}\text { Low No. } \\
(\%)\end{array}$ & $\begin{array}{l}\text { Yes, No. } \\
(\%)\end{array}$ & $\begin{array}{l}\text { No, No. } \\
(\%)\end{array}$ \\
\hline \multicolumn{9}{|c|}{ Concerned about AIDS stigma } \\
\hline Yes & $16(19.0)$ & $68(81.0)$ & $47(56.0)$ & $37(44.0)$ & $47(56.0)$ & $37(44.0)^{*}$ & $51(60.7)$ & $33(39.3)^{\star}$ \\
\hline No & $3(27.3)$ & $8(72.7)$ & $3(27.3)$ & $8(72.7)$ & $2(18.2)$ & $9(81.8)$ & $3(27.3)$ & $8(72.7)$ \\
\hline \multicolumn{9}{|c|}{ Received infant feeding counselling during ANC } \\
\hline Yes & $18(27.3)$ & $48(72.7)^{\star}$ & $41(62.1)$ & $25(37.9)^{*}$ & $42(63.6)$ & $24(36.4)^{*}$ & $44(66.7)$ & $22(33.3)^{\star}$ \\
\hline No & $1(3.6)$ & 27 (96.4) & $8(28.6)$ & 20 (71.4) & 7 (25.0) & $21(75.0)$ & $10(35.7)$ & $18(64.3)$ \\
\hline \multicolumn{9}{|c|}{ Believed breastfeeding transmits HIV to baby } \\
\hline Yes & $14(25.9)$ & $40(74.1)$ & $38(70.4)$ & $16(29.6)^{\star}$ & 39 (72.2) & $15(27.8)^{*}$ & - & - \\
\hline No & $5(19)$ & $37(77)$ & $12(28.6)$ & 30 (71.4) & $10(23.8)$ & $32(76.2)$ & - & - \\
\hline \multicolumn{9}{|c|}{ Knowledge of PMTCT } \\
\hline High & $13(26.0)$ & $37(74.0)$ & - & - & - & - & $38(76.0)$ & $12(24.0)^{*}$ \\
\hline Low & $6(13.0)$ & $40(87.0)$ & - & - & - & - & $16(34.8)$ & $30(65.2)$ \\
\hline \multicolumn{9}{|c|}{ Knowledge about PMTCT related to breastfeeding } \\
\hline High & $9(18.4)$ & $40(81.6)$ & - & - & - & - & $39(79.6)$ & $10(20.4)^{*}$ \\
\hline Low & $10(21.3)$ & $37(78.7)$ & - & - & - & - & $15(31.9)$ & $32(68.1)$ \\
\hline
\end{tabular}

The Botswana Government had promoted EFF by HIV-infected women for many years but presently allows these women to make informed infant feeding choices. ${ }^{3}$ However, informed decision-making can only take place when the women are provided with individualised, unbiased and accurate information about infant feeding options, and when this information is presented in a way that is compatible with women's beliefs and at an appropriate health literacy level. ${ }^{17}{ }^{19}$ This underscores the need for training and retraining of maternal and child health workers in the rationale, principles and methods of infant feeding counselling in the context of HIV infection, based on the WHO and national guidelines on infant feeding in the context of HIV. ${ }^{39}$ Similarly, providing every pregnant woman with a brief guidance manual on infant feeding in the context of HIV infection written in the local language and with appropriate pictorial explanations might help to ensure that all deserving mothers have access to uniform standard information based on which they can make informed choices about infant feeding.

The Botswana Family Health Survey showed that only $20 \%$ of mothers breastfed exclusively for the first 6 months. ${ }^{20}$ Similarly, our study found that less than 1 in 5 (19.8\%) HIV-infected mothers chose to exclusively breastfeed their babies. This finding is in agreement with those of Tomasoni et $a l^{21}$ and Hailu ${ }^{18}$ who found similar low rates of EBF among HIV-positive mothers (46\% and $13.4 \%$, respectively).

Previous studies have explored factors associated with choice of breastfeeding among HIV-infected women.
The study by Hailu ${ }^{18}$ found that infant feeding choices made by lactating mothers in Ethiopia were significantly associated with their age, while a South African study reported that sociocultural factors (including social stigma of HIV/AIDS, maternal age and family influences on feeding practices, economic circumstances, beliefs about HIV transmission through breast milk and beliefs about the quality of breast milk compared with formula) influenced the decision to exclusively breastfeed. As demonstrated in our study, counselling on infant feeding during antenatal visits was an important predictor of infant feeding choices.

It is noteworthy that women who did not express concern about AIDS stigma had significantly higher knowledge of PMTCT practices related to infant feeding. This may be an indication of the barrier that AIDS-related stigma poses against the uptake of PMTCT services among HIV-infected pregnant women in the study setting. It is known that for social stigma to present a barrier against the uptake of services, affected individuals must accept the devaluation and discredit that accompany the stigma. They must perceive themselves as guilty of moral transgression and accept the blame put on them.

It is important for PMTCT programmes to address stigma in order to promote service uptake. Since many of the key influences on AIDS-related stigma and discrimination are broad based and deeply rooted with the structures of communities, the most effective interventions would be those with sound theoretical foundations and that include attention to individual as well as social and structural barriers. In a review of AIDS-related 
Table 3 Multilogistic analysis of factors associated with choice of infant feeding options, knowledge of PMTCT and knowledge of PMTCT practices related to breastfeeding

\begin{tabular}{|c|c|c|c|c|}
\hline Variable & $\begin{array}{l}\text { Choice of exclusive } \\
\text { breastfeeding OR } \\
(95 \% \mathrm{Cl})^{\star}\end{array}$ & $\begin{array}{l}\text { High knowledge of } \\
\text { PMTCT OR }(95 \% \text { Cl)† }\end{array}$ & $\begin{array}{l}\text { High knowledge of } \\
\text { PMTCT during } \\
\text { breastfeeding OR } \\
(95 \% \mathrm{Cl}) \dagger\end{array}$ & $\begin{array}{l}\text { Breastfeeding could } \\
\text { transmit HIV to } \\
\text { baby }^{\star}\end{array}$ \\
\hline \multicolumn{5}{|l|}{ Marital status } \\
\hline Single & - & 1 & - & - \\
\hline Married & - & 34.37 (0.72 to 46.77$)$ & - & - \\
\hline Cohabiting & - & $8.17(0.07$ to 13.00$)$ & - & - \\
\hline Separated & - & $0.75(0.02$ to 31.77$)$ & - & - \\
\hline \multicolumn{5}{|l|}{ Educational level } \\
\hline Primary school & - & 1 & - & - \\
\hline Junior secondary & - & 8.81 (0.63 to 21.89$)$ & - & - \\
\hline $\begin{array}{l}\text { Junior secondary } \\
\text { with additional } \\
\text { training }\end{array}$ & - & 6.24 (0.65 to 64.38$)$ & - & - \\
\hline Senior secondary & - & $1.49(0.0 .11$ to 20.57$)$ & - & - \\
\hline $\begin{array}{l}\text { College or } \\
\text { vocational training }\end{array}$ & - & $1.77(0.0 .19$ to 15.82$)$ & - & - \\
\hline University & - & - & - & - \\
\hline \multicolumn{5}{|c|}{ Concerned about HIV stigma } \\
\hline Yes & & & 1 & - \\
\hline No & & & 5.91 (1.69 to 15.56$)$ & - \\
\hline \multicolumn{5}{|c|}{ Received infant feeding counselling during ANC } \\
\hline No & 1 & - & 1 & - \\
\hline Yes & $5.38(1.83$ to 15.81$)$ & - & 5.91 (1.06 to 34.31$)$ & - \\
\hline \multicolumn{5}{|c|}{ Knowledge of PMTCT related to breastfeeding } \\
\hline Yes & - & - & - & 1 \\
\hline No & - & - & - & 9.73 (3.37 to 28.08$)$ \\
\hline
\end{tabular}

stigma in sub-Saharan Africa, Ehiri et $a l^{22}$ presented the case for a multilevel approach that involves action directed at health workers, religious leaders, members of the judicial system, the media, people living with HIV/AIDS and their family members (table 3 ).

HIV-infected pregnant women are encouraged to exclusively breastfeed their infants for at least 6 months with proper HAART in high-income and low-income countries owing to the proven benefits of breastfeeding for both the mother and the infant. ${ }^{23}{ }^{24}$ For example, the results of a clinical trial in Kenya indicated that giving breastfeeding women a triple-antiretroviral regimen from late pregnancy to 6 months after birth is a safe, feasible way to reduce MTCT in resource-limited settings. ${ }^{25}$ A cohort study in India found higher rates of HIV-free survival in breastfed infants, reporting a cumulative 12-month mortality of formula-fed infants of $9.6 \%$ vs $0.68 \%$ among breastfed infants. ${ }^{26}$ Indeed, the WHO's recommendation that all mothers who are known to be HIV-infected either on lifelong antiretroviral therapy or not, and who exclusively breastfeed their infants should do so for 6 months, introduce appropriate complementary foods thereafter and continue breastfeeding for the first 12 months of life is based on a plethora of research that demonstrate the positive effect of EBF on HIV-free survival of infants born to HIV-infected mothers. ${ }^{27-32}$

Evidence shows that there is significant benefit of breastfeeding regardless of the setting as it has been shown to result in positive health outcomes for infants, even in countries with reliable water and sanitation systems, where gastrointestinal problems and other infectious diseases are not a concern. 3334

A majority of the women in this study $(80.2 \%)$ opted to formula feed their babies. This could be explained by the fact that many healthcare workers commonly prescribe or encourage formula feeding despite the availability of evidence supporting EBF where formula feeding is not AFASS. Doherty et $a l^{34}$ conducted a series of qualitative interviews of a prospective cohort of 650 HIV-positive mothers in South Africa and considered the influence of healthcare workers on infant feeding choices. The study concluded that health workers possess significant influence over HIV-infected women's initial infant feeding choices. Doherty et $a l^{34}$ stated that some women expressed feeling pressured or 'forced' by their provider to choose a particular feeding method as a result of their HIV status. Available evidence shows that women who received formula company-produced infant feeding materials from their health providers at 
their first prenatal visit were more likely than those who did not receive these materials to stop breastfeeding before hospital discharge and before 2 weeks postpartum. Those who were uncertain about their decision to breastfeed, or with a plan to breastfeed for 12 weeks or less, and who received the commercial materials from their health providers also had notably lower rates of EBF and overall duration. ${ }^{35}$

Thus, understanding ethical considerations and providing unbiased information about infant feeding options at the provider level have the potential to improve outcomes of PMTCT services in Botswana and similar low-income and middle-income countries where MTCT of HIV is a public health challenge.

\section{Strengths and limitations}

Given the small size of this study, the results provide only a snapshot assessment of the effectiveness of implementation of the Botswana PMTCT guidelines of 2011, which provide HIV-infected pregnant women the opportunity to make informed infant feeding choices. It is important to note that only HIV-infected pregnant women who attended the four study IDCCs during the period of the study period were recruited. Those who attended non-participating IDCCs were not interviewed. These patients might have had different KAP regarding infant feeding choices from those who were interviewed. Therefore, the findings from this study cannot be generalised to all HIV-infected pregnant women in the Botswana National PMTCT programme.

\section{Implications}

Paediatric AIDS remains a major contributor to child mortality in resource-poor countries; thus, interventions that seek to significantly reduce MTCT of HIV have the potential to contribute towards achievement of the Millennium Development Goal of reducing child mortality by two-thirds by 2015 from the 1990 level.

The finding that a majority of the participants do not receive the recommended counselling on infant feeding underscores the need for PMTCT programmes in lowincome countries to take proper care to understand global and national recommendations on infant feeding in the context of HIV and to find appropriate ways to communicate research evidence to HIV-infected women so that they can make informed choices regarding the infant feeding option.

The finding that a majority of the respondents in this study $(92.7 \%, \mathrm{n}=89)$ identified themselves as either single or cohabiting calls for a need to target this population group with interventions to reduce HIV infection through reduction of risky sexual behaviours.

Further research using qualitative or mixed method approaches is needed to explore enablers and barriers in provision of infant feeding counselling recommended for all HIV-infected pregnant women. Efforts should be made to understand health workers' challenges in implementing this recommendation, and the reasons why some HIV-infected women do not receive infant feeding counselling need to be explored. To gather generalisable information that can be used to improve the quality of Botswana's PMTCT programme, it would be beneficial to replicate this study at other IDCC sites as well as antenatal care (ANC) clinics in the country. To effectively improve EBF rates among HIV-infected women, policymakers must make concerted efforts to advocate, promote and sustain the universal HAART programme for pregnant women and strengthen ANC services. The Botswana MoH should provide adequate training of healthcare workers on infant feeding counselling for HIV-infected women to ensure that they are in a good position to provide unbiased and balanced infant feeding counselling to their clients.

\section{Author affiliations}

${ }^{1}$ School of Population, Community \& Behavioural Sciences, University of Liverpool, Liverpool, UK

${ }^{2}$ Botswana-Harvard School of Public Health, AIDS Institute Partnership, Gaborone, Botswana

${ }^{3}$ Department of Social Medicine \& Health Service Management, Third Military Medical University, Chongqing, China

${ }^{4}$ Division of Health Promotion Sciences/Global health Institute, Mel \& Enid Zuckerman College of Public Health, University of Arizona, Tucson, Arizona, USA

Contributors JN participated in the design of the study, collected data (interviews of respondents) and prepared the first draft of the manuscript. NN conducted the literature review and edited drafts of the manuscript. YL conducted the data analysis and participated in the drafting of the manuscript. CMM conducted the literature review and participated in the drafting of the manuscript. JE guided and supervised the conceptualisation and design of the study, provided oversight of quality control of the research implementation, and edited drafts of the manuscript.

Funding This research received no specific grant from any funding agency in the public, commercial or not-for-profit sectors.

Competing interests None.

Patient consent Obtained.

Ethics approval Approval for this study was obtained from the Ethics Committee of the University of Liverpool, England and from the Botswana Ministry of Health through the Health Research and Development Committee (HRDC).

Provenance and peer review Not commissioned; externally peer reviewed.

Data sharing statement No additional data are available.

Open Access This is an Open Access article distributed in accordance with the Creative Commons Attribution Non Commercial (CC BY-NC 3.0) license, which permits others to distribute, remix, adapt, build upon this work noncommercially, and license their derivative works on different terms, provided the original work is properly cited and the use is non-commercial. See: http:// creativecommons.org/licenses/by-nc/3.0/

\section{REFERENCES}

1. Joint United Nations Programme on AIDS. Botswana: HIV and AIDS estimates, 2011. [Online] http://www.unaids.org/en/regionscountries/ countries/botswana/ (accessed 13 Oct 2013).

2. Republic of Botswana. Progress report of the national response to the 2011 declaration of commitments on HIV and AIDS National AIDS Coordinating Agency. [Online] http://www.unaids.org/en/dataanalysis/ knowyourresponse/countryprogressreports/2012countries/ce_BW_ Narrative Report\%5B1\%5D.pdf (accessed 13 Oct 2013).

3. Ministry of Health (Botswana). Botswana National Guidelines Prevention of Mother-to-Child Transmission of HIV. Gaborone, Botswana. [Online] 
http://www.hiv.gov.bw/content/prevention-mother-child-hiv-transmission (accessed 13 Oct 2013).

4. World Health Organization [WHO]. Rapid advice: use of antiretroviral drugs for treating pregnant women and preventing HIV infection in infants. Geneva: Switzerland. 2009a. [Online] http://www.who.int/hiv/ pub/mtct/rapid advice mtct.pdf (accessed 13 Oct 2013).

5. World Health Organization [WHO]. Rapid advice: revised WHO principles and recommendations on infant feeding in the context of HIV. Geneva: Switzerland. 2009b. [Online] http://www.who.int/hiv/ pub/paediatric/advice/en/ (accessed 13 Oct 2013).

6. Jones G, Steketee RW, Black RE, et al. How many child deaths can we prevent this year? Lancet 2003;362:65-71.

7. Greiner T. Programs to protect, support, and promote breastfeeding. Encyclopedia on Early Childhood Development. Second Edition. Montreal, Quebec: Centre of Excellence for Early Childhood Development and Strategic Knowledge Cluster on Early Child Development; 2008:1-7. [Online] http://www.child-encyclopedia.com/ documents/GreinerANGxp.pdf (accessed 13 Oct 2013).

8. World Health Organization [WHO] \& United Nations Children's Fund [UNICEF]. Global strategy for infant and young child feeding. Geneva: Switzerland. [Online] http://www.who.int/nutrition/publications/gs_ infant feeding text eng.pdf (accessed 13 Oct 2013).

9. World Health Organization [WHO]. Guidelines on HIV and infant feeding 2010: principles and recommendations for infant feeding in the context of HIV and a summary of evidence. Geneva/New York. 2010. World Health Organization/Joint United National AIDS Program/UNICEF. http://www.who.int/maternal_child_adolescent/ documents/9789241599535/en/ (accessed 10 Oct 2013).

10. Sguassero $\mathrm{Y}$. Optimal duration of exclusive breastfeeding: RHL commentary. In: The WHO reproductive health library. Geneva, Switzerland: World Health Organization. 2008. [Online] http://apps. who.int/rhl/pregnancy_childbirth/care_after_childbirth/yscom/en/ (accessed 13 Oct 2013).

11. World Health Organization [WHO]. HIV and infant feeding technical consultation-consensus statement. October 25-27, 2006. Geneva: Switzerland. [Online] http://www.who.int/child-adolescenthealth/ publications/NUTRITION/consensusstatement.htm (accessed 10 Oct 2013)

12. World Health Organization [WHO]. Integrated Management of Childhood IIInesses (IMCI) Complementary course on HIVIAIDS; module 3: counseling the HIV Positive Mother. Geneva: Switzerland, 2007. [Online] http://whqlibdoc.who.int/publications/2006/ 9789241594370.m3_eng.pdf (accessed 10 Oct 2013).

13. Woldesenbet S, Jackson D. The impact of quality of antenatal HIV counselling on HIV-free survival. Abstract WEPED226, 5th IAS Conference on HIV Pathogenesis, Treatment and Prevention, Cape Town, South Africa, 19-22 July 2009.

14. Chopra M, Doherty T, Jackson D, et al. Preventing HIV transmission to children: quality of counseling of mothers in South Africa. Acta Peadiatr 2005;94:257-63.

15. Bruce N, Pope D, Stanistreet D. Quantitative research methods for health research: a practical interactive guide to epidemiology and statistics. Chichester, UK: J Wiley \& Sons Ltd, 2008.

16. Oladokun RE, Brown BJ, Osinusi K. Infant-feeding pattern of HIV-positive women in a prevention of mother-to-child transmission (PMTCT) programme. AIDS Care 2010;22:1108-14.

17. Thairu LN, Pelto GH, Rollins NC, et al. Sociocultural influences on infant feeding decisions among HIV-infected women in rural Kwa-Zulu Natal, South Africa. Matern Child Nutr 2005;1:2-10.

18. Hailu C. Assessment of KAP among mothers about VCT and feeding of infants born to HIV positive women in Jimma town, Ethiopia. Unpublished MPH (Community Health) thesis. Addis Ababa: University of Addis Ababa, 2005.
19. Kanj M, Mitic W. Promoting health and development: closing the implementation gap. Unpublished Conference Document, 7th Global Conference on Health Promotion. Nairobi, Kenya: October 2009. http://www.who.int/healthpromotion/conferences/7gchp/Track1 Inner.pdf (accessed 10 Oct 2013).

20. Sennamose O. Breastfeeding declines DailyNews, 3 August 2012, p.7.

21. Tomasoni LR, Galli M, Declich S, et al. Knowledge, attitudes and practice (KAP) regarding newborn feeding modalities in HIV-infected and HIV-uninfected pregnant women in sub-Saharan Africa: a multicentre study. Int Health 2011;3:56-65.

22. Ehiri JE, Anyanwu EC, Donath E, et al. AIDS-related stigma in sub-Saharan Africa: its contexts and potential intervention strategies. AIDS Public Policy J 2005;20:25-39.

23. World Health Organization (2010b). Guidelines on HIV and infant feeding: principles and recommendations for infant feeding in the context of HIV and a summary of evidence. Geneva: Switzerland. [Online] http:// apps.who.int/iris/bitstream/10665/44345/1/9789241599535_eng.pdf (accessed 10 Oct 2013)

24. Coovadia H, Kindra G. Breastfeeding to prevent HIV transmission in infants: balancing pros and cons. Curr Opin Infect Dis 2008;21:11-15

25. Thomas TK, Masaba R, Borkowf CB, et al. Triple-antiretroviral prophylaxis to prevent mother-to-child HIV transmission through breastfeeding - the Kisumu breastfeeding study, Kenya: a clinical trial. PLoS Med 2011;8:e1001015.

26. Alvarez-Uria G, Midde M, Pakam R, et al. Effect of formula feeding and breastfeeding on child growth, infant mortality, and HIV transmission in children born HIV-infected pregnant women who received triple antiretroviral therapy in a resource-limited setting: data from an HIV cohort study in India. ISRN Pediatr 2012;2012:763591.

27. Mbori-Ngacha D, Nduati R, John G, et al. Morbidity and mortality in breastfed and formula-fed infants of HIV-1-infected women: a randomized clinical trial. JAMA 2001;286:2413-20.

28. Lockman S, Smeaton L, Shapiro R, et al. Morbidity and mortality among infants born to HIV-infected mothers and randomized to breastfeeding versus formula-feeding in Botswana (MASHI study). Abstract TuPE0357, XVI International AIDS Conference, Toronto, Canada, 13-18 August 2006.

29. Kuhn L, Sinkala M, Kankasa C, et al. High uptake of exclusive breastfeeding and reduced early post-natal HIV transmission. PLoS ONE 2007;26;2:e1363.

30. Becquet R, Bequet L, Ekouevi DK, et al. Two-year morbidity-mortality and alternatives to prolonged breast-feeding among children born to HIV-infected mothers in Cote d'Ivoire. PLoS Med 2007;4:e17.

31. Becquet R, Ekouevi DK, Sakarovitch C, et al. Two-year morbidity and mortality in breastfed and formula-fed children born to HIV-infected mothers. ANRS 1201/1202 Ditrame plus, Abidjan, Côte d'Ivoire. Abstract TUPE0350, XVI International AIDS Conference, Toronto, Canada, 13-18 August 2006.

32. Becquet R, Bland R, Leroy V, et al. Duration, pattern of breastfeeding and postnatal transmission of HIV: pooled analysis of individual data from West and South African cohorts. PLOS ONE 2009;4:e7397.

33. Scariati PD, Grummer-Strawn LM, Fein SB. A longitudinal analysis of infant morbidity and the extent of breastfeeding in the United States. Pediatrics 1997;99:E5.

34. Doherty T, Chopra M, Nkonki L, et al. Effect of the HIV epidemic on infant feeding in South Africa: 'When they see me coming with the tins they laugh at me'. Bull World Health Organ 2006;84:90-6.

35. Howard CR, Howard FM, Lawrence R, et al. Office prenatal formula advertising and its effect on breast-feeding patterns. Obstet Gynecol 2000;95:296-303. 